\title{
Stabilitas Tanah Dengan Penambahan Abu Sabut Kelapa Untuk Meningkatkan Daya Dukung
}

\author{
Dr. Ir. H. Abdul Fatah, Dipl.GD, M.T \\ Fakultas Teknik, Program Studi Sipil \\ Universitas Langlangbuana \\ Jl. Karapitan 116, Bandung
}

\begin{abstract}
Abstrak - Tanah memiliki sifat yang unik, karena itu untuk setiap daerah keadaan tanahnya memiliki sifat-sifat yang berbeda. Untuk mengetahui sifat dan kekuatan tanah perlu dilakukan penelitian. Tujuannya setiap kawasan yang diperuntukan untuk konstruksi bangunan dapat digunakan sebagaimana mestinya dan tidak menimbulkan masalah. Tanah yang mengandung mineral monmorilonite, apabila kondisi kering cepat mengkerut tampak di permukaan tanah retak-retak dan sebaliknya jika kena air cepat mengembang, bahkan cepat menjadi bubur. Dengan melalui percobaan stabilisasi tanah yang dicampur dengan Abu Sabut Kelapa (ASK) yang mengandung silika tinggi, maka tanah campuran akan memiliki sifat pozzolon ( Bakri : 2008). Abu Sabut Kelapa (ASK) yang digunakan adalah sisa pembakaran ASK dari daerah Cibodas Kecamatan Jatiwangi. Dalam penelitian ini kami lakukan pengujian CBR unsoaked dengan waktu peraman yang berbeda serta campuran yang berbeda pula. Hasilnya dapat Meningkatkan Stabilitas Tanah, hasil Triaksial UU untuk campuran ASK sebesar 5\%,10\% dan 15\% dapat menaikan nilai kohesive (c) . Dari hasil uji Triaksial UU nilai optimum penambahan Abu Sabut Kelapa (ASK) terjadi pada campuran 10\%.
\end{abstract}

Kata Kunci : Abu Sabut Kelapa, Uji Triaksial, CBR, Sudut Gesr Dalam

\section{PENDAhUluan}

Tujuan utama penelitian ini adalah untuk memperbaiki tanah dan tanah yang lunak dengan daya dukung rendah, sehingga dapat digunakan untuk berdirinya suatu bangunan yang kokoh dengan stabilitas tanah yang tinggi. Fenomena berdirinya bangunan untuk rumah tinggal, pada umumnya tidak memperhatikan terhadap kualitas daya dukung tanah, tetapi hanya dilihat dari segi kuantitas saja, seperti tanah yang rendah tinggal ditinggikan, tanah berbukit tinggal diratakan dan dipadatkan, padahal setelah bangunan berdiri selanjutnya akan muncul masalah dampak dari tidak memperhitungkan daya dukung tanah, dan akan berdampak pada struktur bangunan, sehingga menimbulkan penurunan pada bangunan dengan ditandai dengan adanya retak-retak pada dinding dan bangunan lainnya. Dampaknya bangunan tidak kuat dan bertahan lama akibat dari pada daya dukung tanah yang rendah, begitu pula berlaku untuk jalan, bendungan dan bangunan sipil lainnya.

Setelah dilakukan penelitian dengan melakukan pengujian campuran tanah asli dengan Abu Sabut Kelapa (ASK) lahan/tanah tersebut menjadi stabil dan memiliki daya dukung yang tinggi.

\subsection{Tujuan Penelitian}

Penelitian ini diharapkan dapat memberikan :

a. Informasi mengenai alternative peningkatan daya dukung tanah,

b. Tanah di banyak tempat yang akan didirikan bangunan diharapkan dapat berdiri dengan kokoh dan stabil.

\subsection{Ruang Lingkup}

1) Lingkup pembahasan mengenai daya dukung tanah hasil campuran abu sabut kelapa, dibatasi sebagi berikut : 
a. Lokasi daerah Gedebage Kota Bandung, yang diambil sample berupa tanah dengan plastisitas tinggi yang mengandung mineral monmorilonite, tanah diambil pada kedalaman kurang lebih 0,5 meter

b. Data

- Indek properties tanah asli

- Ukuran butir

- Hasil uji proctor

- Abu Sabut Kelapa (ASK) dengan campuran $10 \%$, dan $15 \%$ sebagai variasi campuran dengan sampel tanah asli.

2) Daya Dukung

Pengertian Daya Dukung tanah.

Daya dukung tanah adalah kemampuan tanah untuk menahan atau mempertahankan posisi/kedudukan butir-butir tanah asli pada beban struktur yang bekerja diatasnya. Jika tanah dikatakan mempunyai daya dukung rendah artinya terjadi ekses-ekses pada lapisan tanah seperti mendapat penurunan pergeseran dan lain sebagainya, yang bisa berdampak kepada struktur bangunan-bangunan yang terdapat diatasnya dan bisa berakibat bangunan bisa ambruk.

3 ) Rencana penelitian campuran tanah asli dengan abu serabut kelapa untuk meningkatkan daya dukung tanah maka dibuat design abu sabut kelapa dengan tanah asli sebagai berikut :

a. Melakukan pengujian sampel tanah dengan campuran abu sabut kelapa ( $10 \%)$

b. Melakukan pengujian sampel tanah dengan campuran abu sabut kelapa ( $15 \%)$

\section{Pengambilan Data Sampel}

\section{Lokasi Pengambilan Sampel}

Dalam studi eksperimental ini, sampel tanah yang digunakan diambil dari Kota Bandung. Tanah yang diambil berupa tanah lanau dengan plastisitas tinggi yang mengandung mineral Monmorilonite. Lokasi pengambilan sampel tanah diambil pada area Gedebage. Tanah diambil pada kedalaman $\pm 0,5 \mathrm{~m}$.

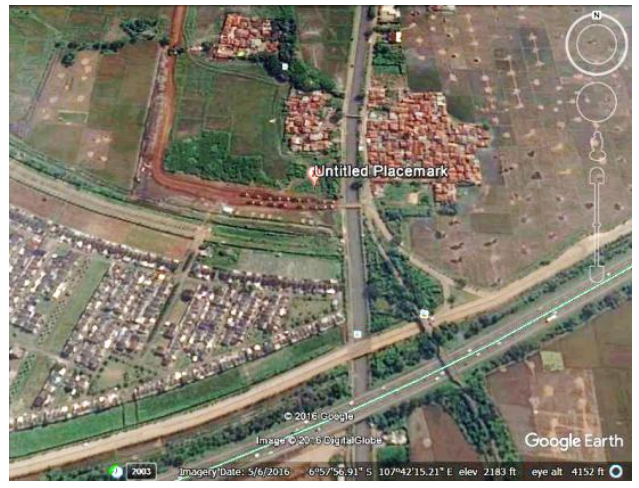

Gambar 2.1Peta Lokasi Pengambilan Sampel Tanah

Pengambilan sampel tanah, terlebih dahulu dicangkul dengan kedalaman kurang lebih 0,5 meter. Kemudian sampel tanah dijemur didiamkan agar sampel tanah kering alami, proses pengeringan ini agar mempermudah proses penyaringan.

\subsection{Bahan Aditif Abu Sabut Kelapa}

Pada uji sampel tanah digunakan campuran Abu Serabut Kelapa (ASK) dengan persentase campuran $10 \%$ dan $15 \%$, Abu Sabut Kelapa yang digunakan dalam kondisi curing. Variasi campuran tersebut untuk mengetahui pengaruh terhadap kenaikan CBR dan sudut geser dalam ( $\phi)$ pada uji Trikasial UU (Unconsolidated Undrained). Abu Sabut Kelapa didapat dari Cibodas Jatiwangi Kabupaten Majalengka. Abu Sabut Kelapa adalah hasil pembakaran sabut kelapa.
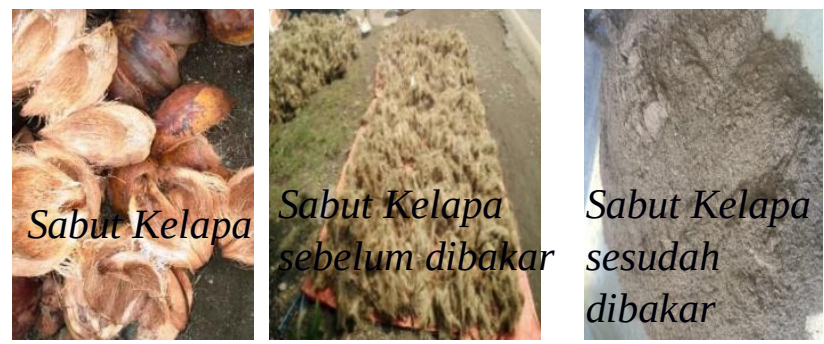

Gambar 2.2 Bahan Aditif Abu Sabut Kelapa 
Tabel 2.1 Komposisi Kimia Abu Sabut Kelapa

Table 1. Composition of lignin residues.

\begin{tabular}{|c|c|c|}
\hline Ultimate Analysis & $\begin{array}{l}\text { Hardwood Lignin } \\
(\% \text { dry matter })\end{array}$ & $\begin{array}{l}\text { Softwood Lignin } \\
\text { (\% dry matter) }\end{array}$ \\
\hline $\mathrm{C}$ & 51.20 & 62.17 \\
\hline H & 5.70 & 5.89 \\
\hline N & 1.07 & 0.15 \\
\hline S & 0.24 & 0.06 \\
\hline $\mathrm{Cl}$ & 0.04 & - \\
\hline Ash & 3.40 & 0.62 \\
\hline$O$ (by difference) & 38.39 & 31.11 \\
\hline Elemental Analysis of Ash * & (\% ash) & $(\%$ ash $)$ \\
\hline$\overline{\mathrm{SiO}_{2}}$ & 16.59 & 47.02 \\
\hline
\end{tabular}

Karakteristik tanah menggunakan abu sabut kelapa tergantung dari jenis tanah, tingkat pembakaran abu sabut kelapa, jumlah ( persentase ) abu sabut kelapa yang digunakan, dan kondisi curing.

\subsection{Hasil Pengujian Awal Tanah Asli}

\subsubsection{Index Properties Tanah}

Pertama dilakukan uji Indeks Properties hasilnya sebagai berikut :

Tabel 2.2 Indeks properti tanah asli

\begin{tabular}{|l|l|}
\hline Parameter & Hasil \\
\hline Kadar Air Alami (\%) & 39,03 \\
\hline Berat Isi Tanah Basah (g/cm3) & 1,64 \\
\hline Berat Isi Tanah Kering (g/cm3) & 1,23 \\
\hline Gs & 2,70 \\
\hline Batas Plastis (\%) & 37,97 \\
\hline Batas Cair, WL (\%) & 70,50 \\
\hline Batas Cair Oven, WLoven (\%) & 65,50 \\
\hline Indeks Plastisitas & 32,53 \\
\hline \% Finer & 69,95 \\
\hline Klasifikasi Tanah (USCS) & OH \\
\hline Jenis Tanah & Anorganik \\
\hline Activity & 0,4650 \\
\hline
\end{tabular}

Maka, tanah ini termasuk ke dalam kelompok anorganik dan lempung organik dengan plastisitas tinggi $(\mathrm{OH})$

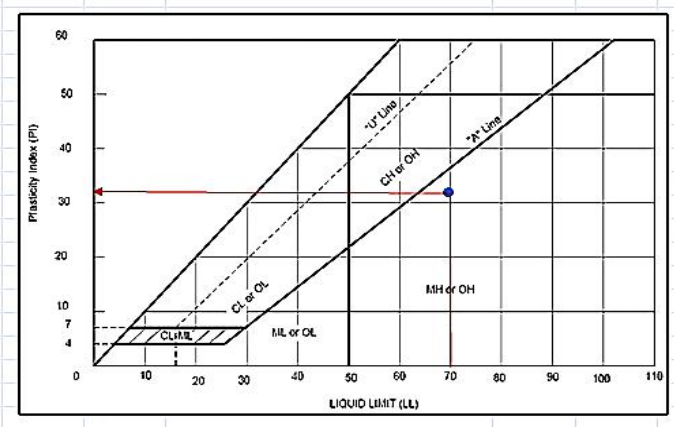

Gam

bar 2.3Grafik diagram plastisitas

\subsubsection{Uji Saringan dan Uji Hidrometer}

Setelah uji indeks propertis tanah, kemudian dilakukan uji saringan dan uji hidrometer, uji saringan dan uji hidrometer yang dilakukan adalah uji saringan basah. Uji ini untuk mengetahui distribusi ukuran butir tanah. Berikut ini merupakan kurva hasil uji saringan dan uji hidrometer,

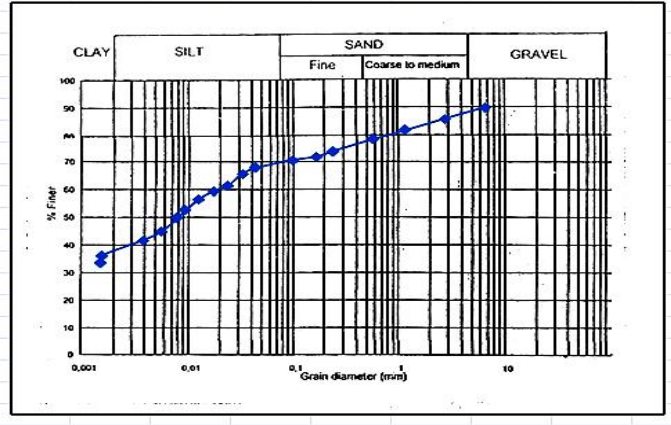

Gambar 2.4 Kurva distribusi ukuran butir uji saringan dan hidrometer

Berikut pula adalah tabel persentase jenis tanah :

Tabel 2.3Tabel persentase jenis tanah hasil uji saringan dan hidrometer

\begin{tabular}{|l|l|}
\hline Gravel & 10,7486 \\
\hline Medium sand & 11,4929 \\
\hline Fine sand & 7,81867 \\
\hline Silt clay & 69,9398 \\
\hline Silt & 17,0275 \\
\hline Clay & 52,9124 \\
\hline$D_{10}$ & - \\
\hline$D_{30}$ & - \\
\hline$D_{60}$ & 0,02 \\
\hline$C_{u}$ & - \\
\hline$C_{c}$ & - \\
\hline
\end{tabular}

Dari hasil uji saringan dan hidrometer, terbukti bahwa sampel tanah adalah tanah lempung kelanauan dengan persentase lempung sebesar 52,91\%.

\subsection{Uji Kompaksi}

Uji kompaksi yang dilakukan menggunakan metode standard proctor. Untuk pelaksaan uji kompaksi standard proctor digunakan 
mold dengan volume 1073,82 cm3. Jumlah lapisan dalam satu mold sebanyak 3 lapis dengan masing-masing lapis ditumbuk sebanyak 25 tumbukan dan berat hammer yang digunakan seberat $2,5 \mathrm{~kg}$.

Uji kompaksi dilakukan untuk mengetahui berat isi kering maksimum dan kadar air optimum. Pengujian dilakukan dengan dua variasi, yaitu tanah asli, tanah asli dicampur $10 \%$ abu sabut kelapa, dan tanah asli dicampur abu sabut kelapa 15\%. Sehingga didapat dua nilai yang berbeda. Untuk pengujian uji kompaksi tanah yang dicampur abu sabut kelapa, tanah sudah terlebih dahulu dicampur dan didiamkan selama 24 jam, dan 3 hari, agar bahan campuran abu sabut kelapa dan tanah bereaksi. Berikut hasil pengujian kompaksi.

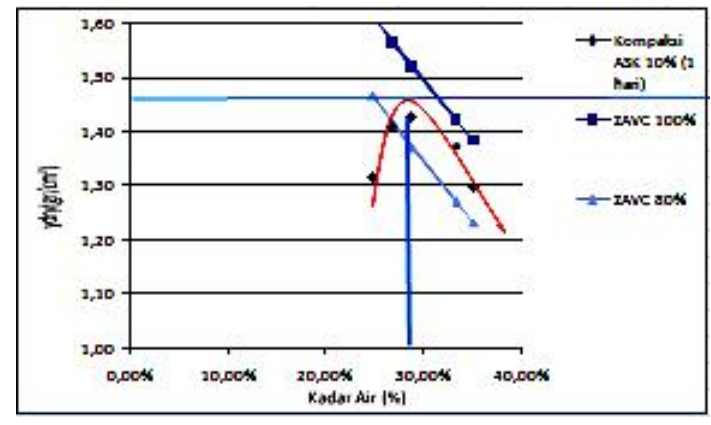

Gambar 2.5Grafik kompaksi tanah + ASK 10\%

(curing 24 jam)

Dari grafik kompaksi tanah + ASK $10 \%$ (curing 24jam), diperoleh:

Kadar air optimum, Woptimum : $28 \%$..Berat isi kering maksimum, adry maks : $1,438 \mathrm{~g} / \mathrm{cm}^{3}$

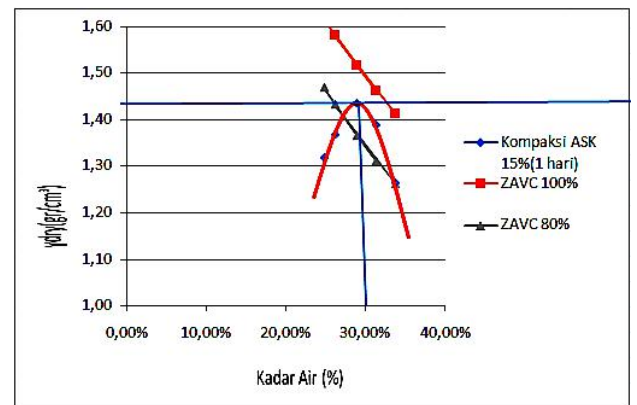

Gambar 2. 6Grafik kompaksi tanah + ASK 15\% (curing 24 jam )

Dari grafik kompaksi tanah + ASK $15 \%$ (curing 24 jam), diperoleh:

Kadar air optimum, Woptimum : 30\%
Berat isi kering maksimum, $\gamma$ dry maks : $1,417 \mathrm{~g} / \mathrm{cm}^{3}$

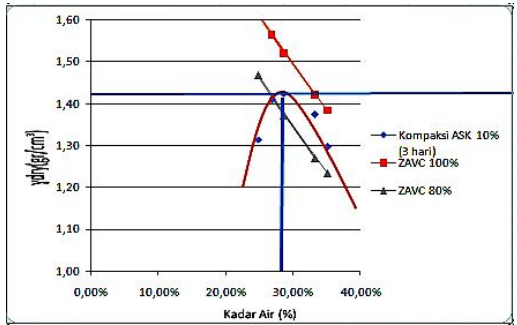

Gambar 2. 7Grafik kompaksi tanah + ASK 10\% (curing 3 hari)

Dari grafik kompaksi tanah + ASK $10 \%$ (curing 3 hari), diperoleh:

Kadar air optimum, Woptimum : $28,91 \%$

Berat isi kering maksimum, $\square$ dry maks : $1,159 \mathrm{~g} / \mathrm{cm}^{3}$

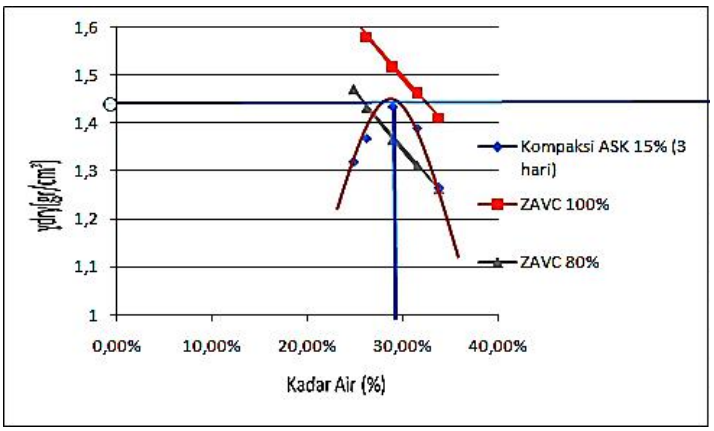

Gambar 2. 8Grafik kompaksi tanah + ASK 15\% ( curing 3 hari)

Dari grafik kompaksi tanah + ASK $15 \%$ (curing 3 hari), diperoleh:

Kadar air optimum, Woptimum : 28,89 \%

Berat isi kering maksimum, $\gamma$ dry maks : $1,414 \mathrm{~g} / \mathrm{cm}^{3}$

Agar memudahkan pembacaan hasil kompaksi tanah asli dan campuran adalah dengan menggunakan tabel.

Berikut adalah tabel hasil kompaksi tanah asli dan tanah yang dicampur dengan abu serabut kelapa (ASK): 
Tabel 2.4 Tabel hasil kompaksi dari berbagai variasi campuran dan masa curing

\begin{tabular}{|c|c|c|c|c|}
\hline $\begin{array}{l}\text { Variasi } \\
\text { campuran } \\
(\% \text { ASK) }\end{array}$ & $\begin{array}{l}\text { masa } \\
\text { curing }\end{array}$ & $\begin{array}{l}\text { Woptimum } \\
(\%)\end{array}$ & $\begin{array}{l}\gamma \text { dry } \\
\text { maks } \\
(\mathrm{g} / \mathrm{cm} 3)\end{array}$ & Gs \\
\hline Tanah asli & 0 & $31 \%$ & 1,390 & 2,70 \\
\hline $\begin{array}{c}\text { Tanah } \\
+10 \% \text { ASK }\end{array}$ & 24 jam & $28 \%$ & 1,438 & 2,70 \\
\hline $\begin{array}{c}\text { Tanah + 15 } \\
\% \text { ASK }\end{array}$ & $30 \%$ & 1,417 & 2,70 \\
\hline $\begin{array}{c}\text { Tanah + 10 } \\
\% \text { ASK }\end{array}$ & 3 hari & $28,91 \%$ & 1,159 & 2,70 \\
\hline $\begin{array}{l}\text { Tanah + } \\
15 \% \text { ASK }\end{array}$ & $28,89 \%$ & 1,414 & 2,70 \\
\hline
\end{tabular}

\section{HASIL UJI CBR}

\subsection{Tanah Asli}

Sampel Uji 1 (Tanah Asli)

Tabel 3.5Tabel Hasil Uji CBR Tanah Asli

\begin{tabular}{|c|c|c|}
\hline Jumlah Tumbukan & & Nilai CBR (\%) \\
\hline 10 & 1,172 & 8,89 \\
\hline 25 & 1,319 & 10,88 \\
\hline 56 & 1,425 & 20,49 \\
\hline \multicolumn{2}{|c|}{ CBR rata-rata } & 13,42 \\
\hline
\end{tabular}

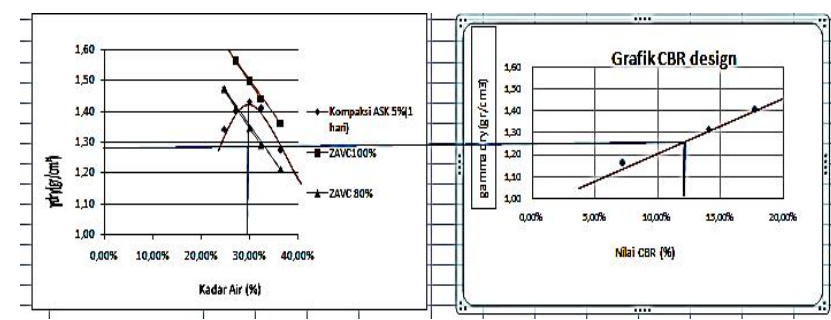

Gambar 3.9Kurva CBR Design Tanah Asli

Nilai CBR design yang diperoleh $=$ $13,50 \%$

\subsubsection{Tanah dengan Campuran Abu Sabut Kelapa}

Sampel Uji 2 Campuran (Masa Curing 1 hari)

Tabel 3.6Tabel Hasil Uji CBR Tanah Asli + Abu sabut kelapa $10 \%$

\begin{tabular}{|c|l|c|}
\hline Jumlah Tumbukan & $\gamma_{\text {dry }}$ & Nilai CBR (\%) \\
\hline 10 & 1,138 & 7,80 \\
\hline & & \\
\hline 25 & 1,326 & 16,86 \\
\hline 56 & 1,477 & 24,48 \\
\hline \multicolumn{2}{|c|}{ CBR rata-rata } & 16,38 \\
\hline
\end{tabular}

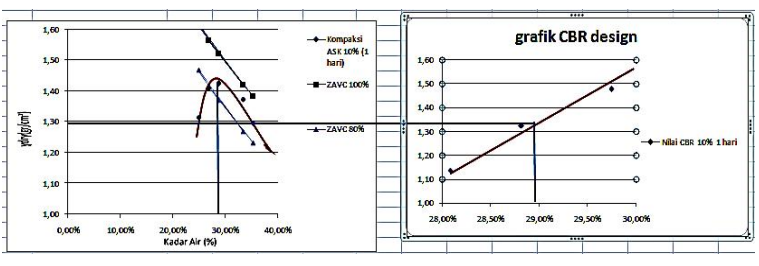

Gambar 3.10Kurva CBR Design Tanah Asli + Abu sabut kelapa $10 \%$

Nilai CBR design yang diperoleh $=28,86$

Tabel 3.7 Tabel Hasil Uji CBR Tanah Asli + Abu sabut kelapa $15 \%$

\begin{tabular}{|c|c|c|}
\hline Jumlah Tumbukan & $\gamma_{\text {dry }}$ & Nilai CBR (\%) \\
\hline 10 & 1,132 & 6,66 \\
\hline 25 & 1,216 & 9,94 \\
\hline 56 & 1,318 & 17,41 \\
\hline \multicolumn{2}{|c|}{ CBR rata-rata } & 11,33 \\
\hline
\end{tabular}

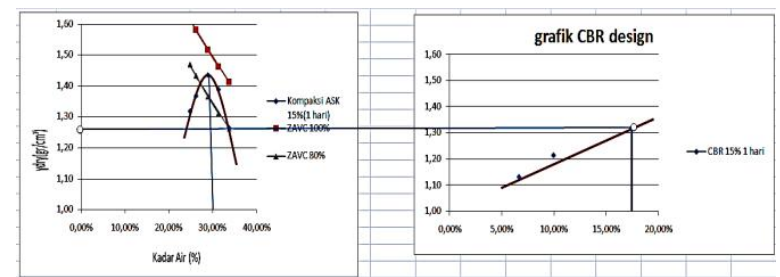

Gambar 3.11 Kurva CBR Design Tanah Asli + Abu sabut kelapa $15 \%$

Nilai CBR design yang diperoleh $=17,50 \%$

\subsubsection{Sampel Uji 3 Campuran (Masa Curing 3 hari)}
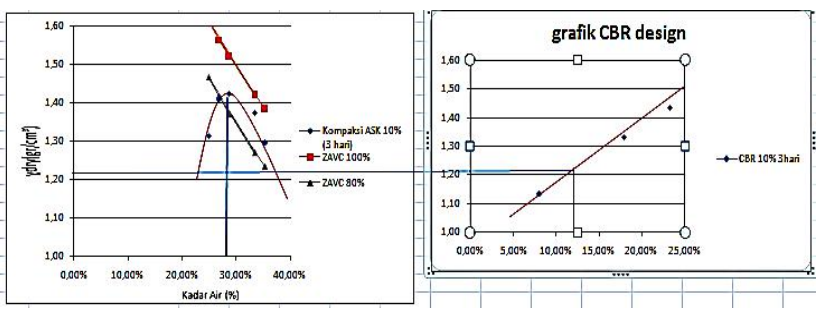

Gambar 3.12 Kurva CBR Design Tanah Asli + Abu sabut kelapa $10 \%$

Nilai CBR design yang diperoleh $=12,49 \%$

Tabel 3.8 Tabel Hasil Uji CBR Tanah Asli + Abu Sabut Kelapa $15 \%$

\begin{tabular}{|c|c|c|}
\hline Jumlah Tumbukan & $\gamma_{\text {dry }}$ & Nilai CBR (\%) \\
\hline 10 & 1,086 & 6,35 \\
\hline 25 & 1,289 & 14,01 \\
\hline 56 & 1,381 & 21,71 \\
\hline CBR rata-rata & 14,02 \\
\hline
\end{tabular}


Dari keterangan gambar diatas dapat dilihat bahwa dalam waktu 3 hari nilai CBR mengalami kenaikan. Secara signifikan baru terlihat pada umur 3 hari. Sedangkan pada umur 24 jam, belum terlalu terlihat.

Tabel 3.9 Tabel CBR Rata-Rata Lab dan CBR Design

\begin{tabular}{|c|c|c|c|}
\hline $\begin{array}{l}\text { Variasi } \\
\text { campuran (\% } \\
\text { ASK) }\end{array}$ & $\begin{array}{l}\text { masa } \\
\text { curing }\end{array}$ & $\begin{array}{l}\text { CBR } \\
\text { Rata-rata } \\
\text { Lab (\%) }\end{array}$ & $\begin{array}{l}\text { CBR } \\
\text { Design } \\
(\%)\end{array}$ \\
\hline Tanah asli & 0 & 13,42 & 13,50 \\
\hline $\begin{array}{c}\text { Tanah+10\% } \\
\text { ASK }\end{array}$ & 24 jam & 16,38 & 28,86 \\
\hline $\begin{array}{c}\text { Tanah + 15\% } \\
\text { ASK }\end{array}$ & & 11,33 & 17,50 \\
\hline $\begin{array}{c}\text { Tanah + 10\% } \\
\text { ASK }\end{array}$ & 3 hari & 16,39 & 12,49 \\
\hline $\begin{array}{c}\text { Tanah +15\% } \\
\text { ASK }\end{array}$ & & 14,02 & 21,50 \\
\hline \multicolumn{2}{|c|}{} \\
\hline
\end{tabular}

\section{Hasil UJi Triaksial UU}

Uji triaksial yang dilakukan menggunakan uji Triaksial UU (unconsolidated undrained) berdasarkan standar ASTM D-2850-15 mengenai uji Triaksial UU. Untuk pelaksaan uji Triaksial UU menggunakan 3 buah mold untuk satu variasi. Pemberian tegangan keliling didalam sel Triaksial pada setiap kali uji triaksial UU berbeda, mulai 0,5 $\mathrm{kg} / \mathrm{cm}^{2}, 1 \mathrm{~kg} / \mathrm{cm}^{2}$ dan $2 \mathrm{~kg} / \mathrm{cm}^{2}$. Kalibrasi alat uji triaksial yang digunakan adalah $0,9072 \mathrm{~kg} / \mathrm{div}$.

Uji Triaksial UU dilakukan untuk mengetahui nilai kohesi tanah (c) dan

sudut geser dalam tanah $(\phi)$. Pengujian

dilakukan dengan sepuluh variasi, yaitu tanah asli, tanah asli dicampur 10\% Abu Sabut Kelapa, dan tanah asli dicampur Abu Sabut Kelapa 15\%. Sehingga, didapat sepuluh nilai yang berbeda. Untuk pengujian uji Triaksial UU tanah yang dicampur abu serabut kelapa, tanah sudah terlebih dahulu dicampur dan didiamkan selama 24 jam dan 3 hari agar bahan campuran abu sabut kelapa dan tanah bereaksi.

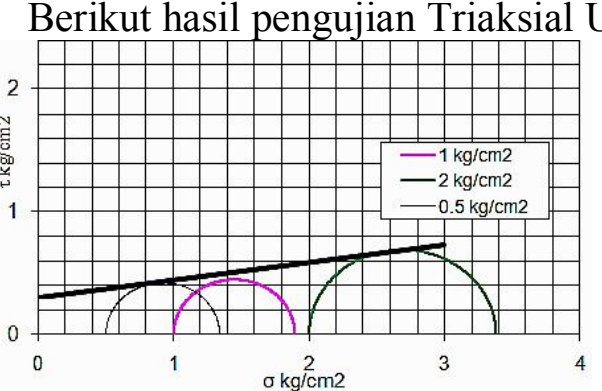

Gambar 4.14Grafik lingkaran mohr hasil uji Triaksial tanah asli

Dari grafik lingakaran Mohr Uji Triaksial tanah asli, diperoleh:

Kohesi tanah, c : $0,3 \mathrm{~kg} / \mathrm{cm}^{2}$

Sudut geser dalam, $\phi: 8,16^{0}$

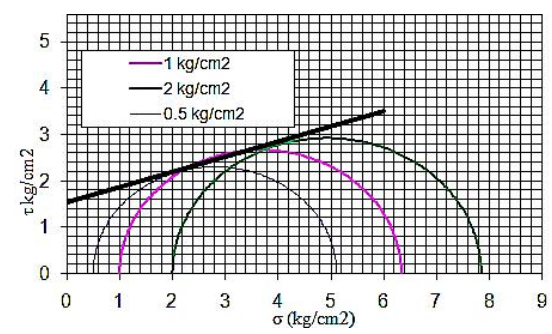

Gambar 4.15 Grafik lingkaran mohr hasil uji

Triaksial tanah $+10 \%$ ASK (curing 24 jam)

Dari grafik lingakaran Mohr Uji Triaksial tanah $+10 \%$ ASK (curing 24 jam), diperoleh: Kohesi tanah, c : $1,55 \mathrm{~kg} / \mathrm{cm}^{2}$

Sudut geser dalam, $\phi: 18^{0}$

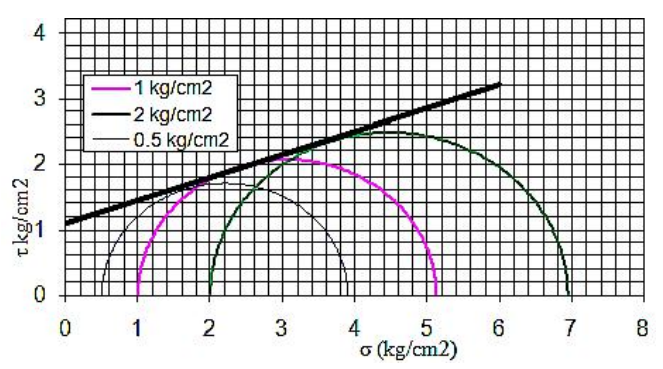

Gambar 4.16 Grafik lingkaran mohr hasil uji Triaksial tanah $+15 \%$ ASK (curing 24 jam)

Dari grafik lingakaran Mohr Uji Triaksial tanah $+15 \%$ ASK (curing 24 jam), diperoleh: 
Kohesi tanah, c : 1,1 kg/cm2

Sudut geser dalam, $\phi: 19,290$

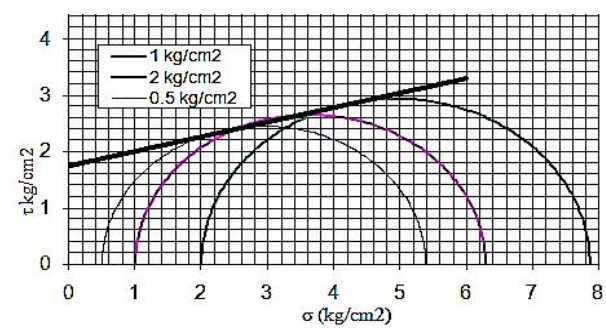

Gambar 4.17 Grafik lingkaran mohr hasil uji

Triaksial tanah $+10 \%$ ASK (curing 3 hari)

Dari grafik lingakaran Mohr Uji Triaksial tanah $+10 \%$ ASK (curing 3 hari), diperoleh:

Kohesi tanah, c $: 1,75 \mathrm{~kg} / \mathrm{cm}^{2}$

Sudut geser dalam, $\phi \quad: 14,48^{0}$

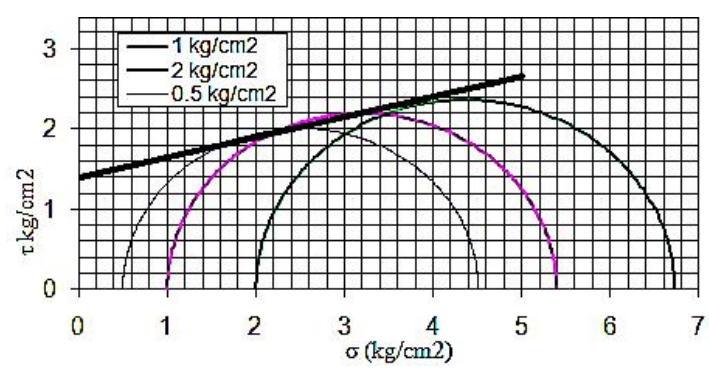

Gambar 4.18 Grafik lingkaran mohr hasil uji Triaksial tanah $+15 \%$ ASK (curing 3 hari)

Dari grafik lingakaran Mohr Uji Triaksial tanah $+15 \%$ ASK (curing 3 hari), diperoleh:

Kohesi tanah, c $: 1,4 \mathrm{~kg} / \mathrm{cm} 2$

Sudut geser dalam, $\phi \quad: 14,040$

Agar memudahkan pembacaan hasil Uji Triaksial UU tanah asli dan campuran bisa menggunakan tabel.

Berikut adalah tabel hasil Uji Triaksial UU tanah asli dan tanah yang dicampur dengan Abu Sabut Kelapa (ASK):
Tabel 4. 10 Tabel hasil Uji Triaksial UU dari berbagai variasi campuran dan masa curing

\begin{tabular}{|c|c|c|c|c|}
\hline $\begin{array}{c}\text { Variasi } \\
\text { campuran } \\
(\% \text { ASK })\end{array}$ & $\begin{array}{c}\text { masa } \\
\text { curing } \\
\text { (jam) }\end{array}$ & $\begin{array}{c}\mathrm{c} \\
(\mathrm{kg} / \mathrm{cm} 2)\end{array}$ & $\Phi\left(^{\circ}\right)$ & Gs \\
\hline Tanah asli & 0 hari & 0.3 & 8,16 & 2,70 \\
\hline $\begin{array}{c}\text { Tanah }+10 \% \\
\text { ASK }\end{array}$ & 1 hari & 1,55 & 18 & 2,70 \\
\hline $\begin{array}{c}\text { Tanah }+15 \% \\
\text { ASK }\end{array}$ & & 1.1 & 19.29 & 2,70 \\
\hline $\begin{array}{c}\text { Tanah }+10 \% \\
\text { ASK }\end{array}$ & 3 hari & 1.75 & 14,48 & 2,70 \\
\hline $\begin{array}{c}\text { Tanah }+15 \% \\
\text { ASK }\end{array}$ & & 1,4 & 14,04 & 2,70 \\
\hline
\end{tabular}

Dari hasil percobaan Uji Triaksial UU, menunjukkan bahwa perubahan variasi campuran dan lama masa pengeraman (curing) berpengaruh pada nilai kohesi tanah (c). Berikut grafik pengaruh perubahan variasi campuran dan masa pengeraman ( curing):

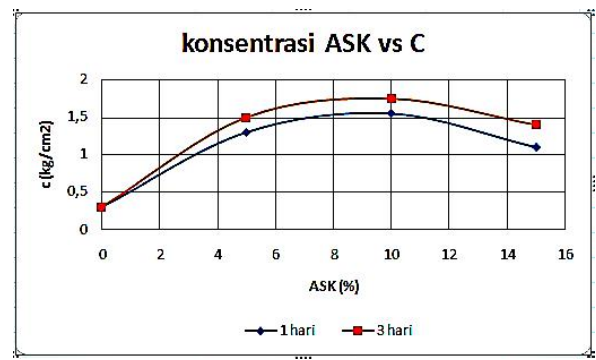

Gambar 4.19 Grafik pengaruh variasi campuran ASK terhadap nilai kohesi (c)

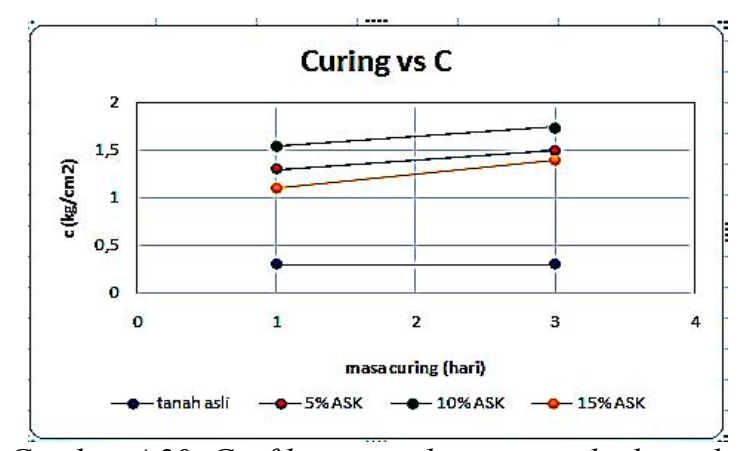

Gambar 4.20 Grafik pengaruh curing terhadap nilai kohesi (c) 
Tabel 4. 11 Tabel hasil Uji penelitian

\begin{tabular}{|c|c|c|c|c|c|c|}
\hline $\begin{array}{l}\text { Persent } \\
\text { ase } \\
\text { Campu } \\
\text { ran dan } \\
\text { Masa } \\
\text { Curing }\end{array}$ & $\begin{array}{l}\text { dr } \\
y \\
\text { Maks } \\
(\mathrm{g} / \mathrm{c} \\
\left.\mathrm{m}^{3}\right)\end{array}$ & $\begin{array}{c}\text { Wo } \\
\text { pt } \\
(\%)\end{array}$ & $\begin{array}{c}\text { Nilai } \\
\text { CBR } \\
\text { Desi } \\
\text { gn } \\
(\%)\end{array}$ & $\begin{array}{c}\mathrm{c} \\
(\mathrm{kg} / \mathrm{c} \\
\left.\mathrm{m}^{2}\right)\end{array}$ & $\begin{array}{l}\text { 命 } \\
(*)\end{array}$ & $\begin{array}{c}\square \\
(\mathrm{kN} / \\
\left.\mathrm{m}^{2}\right)\end{array}$ \\
\hline $\begin{array}{c}\text { Tanah } \\
\text { Asli }\end{array}$ & $\begin{array}{c}1,39 \\
0\end{array}$ & 31 & $\begin{array}{c}13,5 \\
0\end{array}$ & 0,3 & $\begin{array}{c}8,1 \\
6\end{array}$ & 4,28 \\
\hline $\begin{array}{l}\text { Tanah } \\
+ \text { ASK } \\
10 \% \\
\text { curing } \\
1 \text { hari }\end{array}$ & $\begin{array}{c}1,43 \\
8\end{array}$ & 28 & $\begin{array}{c}28,8 \\
6\end{array}$ & 1,55 & 18 & 18,42 \\
\hline $\begin{array}{l}\text { Tanah } \\
+ \text { ASK } \\
15 \% \\
\text { curing } \\
1 \text { hari }\end{array}$ & $\begin{array}{c}1,41 \\
7\end{array}$ & 30 & $\begin{array}{c}17,5 \\
0\end{array}$ & 1,1 & $\begin{array}{l}19, \\
29\end{array}$ & 14,09 \\
\hline $\begin{array}{l}\text { Tanah } \\
+ \text { ASK } \\
10 \% \\
\text { curing } \\
3 \text { hari }\end{array}$ & $\begin{array}{c}1,15 \\
9\end{array}$ & $\begin{array}{c}28 \\
91\end{array}$ & $\begin{array}{c}12,4 \\
9\end{array}$ & 1,75 & $\begin{array}{l}14, \\
48\end{array}$ & 19,87 \\
\hline $\begin{array}{l}\text { Tanah } \\
+ \text { ASK } \\
15 \% \\
\text { curing } \\
3 \text { hari }\end{array}$ & $\begin{array}{c}1,41 \\
4\end{array}$ & $\begin{array}{l}28 \\
89\end{array}$ & $\begin{array}{c}21,5 \\
0\end{array}$ & 1,4 & $\begin{array}{l}14, \\
04\end{array}$ & 16,28 \\
\hline
\end{tabular}

\section{Kesimpulan .}

1. Dengan campuran Abu Sabut Kelapa (ASK) sebesar 10\% untuk tanah yang berplastisitas tinggi dan mengandung mineral monmorilonite dengan uji praktek, nilai $\mathrm{CBR}$ tanahnya meningkat dari $13,50 \%$ menjadi $21,50 \%$ untuk umur 3 hari.

2. Hasil campuran tanah asli $+10 \% \mathrm{Abu}$ Sabut Kelapa dengan curing 1 hari, menunjukan Nilai Kuat Geser terbesar = $18,42 \mathrm{kN} / \mathrm{m}^{2}$, dan untuk 3 hari Nilai Kuat Geser $=19,87 \mathrm{kN} / \mathrm{m}^{2}$.

3. Campuran Optimum Abu Sabut Kelapa (ASK) pada angka $10 \%$.

\section{Daftar Pustaka}

[1] Agustini,w. 2014

http://eprints.polsri.ac.id/972/3/BAB $\% 20$ II.pdf

[2] American Society for Testing Material. (2007). Standar Test Method for CBR (California Bearing Ratio) of Laboratory-Compacted Soil. ASTM designation: D1883 -07e2. Philadelphia, Pa., 309-310

[3] Blunk,S.L dan B.M Jenkins.2000. Combustion Properties of lignin residue from lignocellulose fermentatiom, diakses dari http://home.mtholyoke.edu/course/gtog 304B/4644.PDF, 16 Februari 2017.

[4] Das, B.M, 1993, mekanika tanah jilid I, Erlangga, Ciracas.

[5] Das, B.M, 1994, mekanika tanah jilid II, Erlangga, Ciracas. 
